\section{Commentary: Preventative indications for major resection}

\author{
Jacqueline K. Olive, BA, and Bryan M. Burt, MD
}

Prevention of catastrophic complications is one of the lessfrequent indications for major surgical resection in thoracic surgery. This indication is applied most commonly to patients with advanced cancer in whom a tumor mass is at high risk for invasion into a major vascular structure. Surgical anatomy consequently can be treacherous, and the extent of required resection is typically major. Importantly, the oncologic benefit of surgery in these cases can be difficult to predict. Such patients often have metastatic disease, and in those with only loco-regional disease, feasibility for R0 resection is rarely confidently predictable.

The last decade has ushered in the adoption of immunotherapy from investigational status to first-line therapy for many of the patients whom we treat as thoracic surgeons. Early data from patients treated with neoadjuvant checkpoint blockade for non-small cell lung cancer have demonstrated remarkable pathologic responses in surgical specimens that would have otherwise not been known from cross-sectional imaging. ${ }^{1}$ Checkpoint inhibition has also proven to extend overall and progression-free survival in patients with non-small cell lung cancer and other malignancies. However, individual responses to immunotherapy are heterogeneous, and overall response rates to checkpoint inhibitors including cemiplimab, in particular, remain low. ${ }^{2}$ Defining individualized measures of immunotherapy treatment efficacy remains an ongoing challenge.

In this issue of JTCVS Techniques, Choi and colleagues ${ }^{3}$ at Memorial Sloan-Kettering Cancer Center present a case

From the Division of General Thoracic Surgery, Michael E. DeBakey Department of Surgery, Baylor College of Medicine, Houston, Tex.

Disclosures: The authors reported no conflicts of interest.

The Journal policy requires editors and reviewers to disclose conflicts of interest and to decline handling or reviewing manuscripts for which they may have a conflict of interest. The editors and reviewers of this article have no conflicts of interest.

Received for publication Aug 21, 2020; revisions received Aug 21, 2020; accepted for publication Aug 26, 2020; available ahead of print Sept 15, 2020.

Address for reprints: Bryan M. Burt, MD, Division of General Thoracic Surgery, Michael E. DeBakey Department of Surgery, Baylor College of Medicine, One Baylor Plaza, BCM 390, Houston, TX 77030 (E-mail: bryan.burt@bcm.edu).

JTCVS Techniques 2020;4:334-5

2666-2507

Copyright $(2020$ The Authors. Published by Elsevier Inc. on behalf of The American Association for Thoracic Surgery. This is an open access article under the CC BY-NCND license (http://creativecommons.org/licenses/by-nc-nd/4.0/).

https://doi.org/10.1016/j.xjtc.2020.08.068

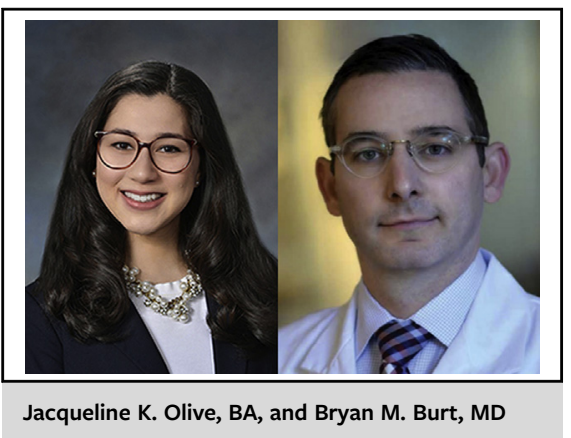

CENTRAL MESSAGE

The penetrance of immunotherapy into the field of thoracic oncology will expand indications for surgery and increase the complexity of surgical decisionmaking.

that illustrates the importance of several of the aforementioned points. Following PD-1 blockade with cemiplimab, and radiotherapy, a 64-year-old woman underwent a complex R0 radical resection of a squamous cell carcinoma of the chest wall and thoracic outlet that was approaching invasion of the subclavian artery and vein. A striking complete pathologic response was found by microscopic examination, and the patient has had no evidence of disease at mid-term surveillance.

This report showcases the evolution of our field, highlighting the expanding indications for major resection in patients treated with immunotherapy and advanced surgical techniques that will be appreciated by our surgeon readership. Reciprocally, the authors offer a balanced message for the careful selection of patients in these difficult situations. We ask the readers to appreciate the breadth and depth of specialty authorship of this manuscript, which includes thoracic surgeons, plastic surgeons, head and neck surgeons, and radiation oncologists. We also ask the readers to notice that this case underwent careful and recurrent multidisciplinary review at an expert center, and that resection and reconstruction were performed by a seasoned surgeon. Our readership understands that thoracic surgeons are more frequently being asked to evaluate patients with advanced tumors that require complex resection and to consider "preventative" indications for high-risk and technically demanding surgery. Whereas this is a single case and a sample size of one, it is representative of the momentum and advances of our field and 
should encourage us to push the envelope yet do so with appropriate caution.

\section{References}

1. Uprety D, Mandrekar SJ, Wigle D, Roden AC, Adjei AA. Neoadjuvant immunotherapy for NSCLC: current concepts and future approaches. J Thorac Oncol. 2020;15:1281-97.
2. Migden MR, Khushalani NI, Chang ALS, Lewis KD, Schmults CD, HernandezAya L, et al. Cemiplimab in locally advanced cutaneous squamous cell carcinoma: results from an open-label, phase 2, single-arm trial. Lancet Oncol. 2020;21: 294-305.

3. Choi JJ, Allen RJ, Bains MS, Cohen MA, Yu Y, Elmadhun N, et al. Complex chest wall surgery to prevent vascular complications after immunotherapy and radiation treatment. J Thorac Cardiovasc Surg Tech. 2020;4:329-31. 